\title{
Colony-stimulating factor-1 and colony-stimulating factor-1 receptor co-expression is associated with disease progression in gastric cancer
}

\author{
YOSHINAGA OKUGAWA $^{1,2}$, YUJI TOIYAMA ${ }^{2}$, TAKASHI ICHIKAWA ${ }^{2}$, MIKIO KAWAMURA $^{2}$, HIROMI YASUDA ${ }^{2}$, \\ HIROYUKI FUJIKAWA ${ }^{2}$, SUSUMU SAIGUSA ${ }^{2}$, MASAKI OHI ${ }^{2}$, TOSHIMITSU ARAKI ${ }^{2}$, KOJI TANAKA ${ }^{1,2}$, \\ YASUHIRO INOUE ${ }^{2}$, MOTOYOSHI TANAKA ${ }^{1}$, CHIKAO MIKI $^{1}$ and MASATO KUSUNOKI ${ }^{2}$ \\ ${ }^{1}$ Department of Surgery and Medical Oncology, Iga City General Hospital, Iga, Mie 518-0823; \\ ${ }^{2}$ Department of Gastrointestinal and Pediatric Surgery, Division of Reparative Medicine, \\ Institute of Life Sciences, Mie University Graduate School of Medicine, Tsu, Mie 514-8507, Japan
}

Received December 21, 2017; Accepted April 10, 2018

DOI: 10.3892/ijo.2018.4406

\begin{abstract}
Colony-stimulating-factor-1 (CSF-1) is a hematopoietic growth factor that exerts its effects through the c-fms/CSF-1 receptor (CSF-1R). The CSF-1/CSF-1R axis is thought to be involved in the development of several types of cancer. This study aimed to clarify the clinical and biological significance of the CSF-1/CSF-1R axis in gastric cancer (GC). For this purpose, we evaluated CSF-1 and CSF-1R expression in GC tissues from 148 patients by RT-qPCR and immunohistochemistry. The biological roles of the CSF-1/CSF-1R axis were investigated by measuring the cell proliferation and migration, and anoikis resistance in a human GC cell line following treatment with recombinant human CSF-1 and/or CSF-1R inhibitor. The results revealed that an elevated expression of CSF-1 or CSF-1R significantly correlated with disease progression and with a poor overall survival $(\mathrm{OS}, \mathrm{P}=0.037$ and 0.016 , respectively) and disease-free survival (DFS, $\mathrm{P}<0.001$ and $<0.001$, respectively) of patients with GC. Furthermore, a high co-expression of CSF-1 and CSF-1R was an independent prognostic factor for OS (HR, 1.38; 95\% CI, 1.02-1.88; $\mathrm{P}=0.038$ ) and DFS (HR, 1.79; 95\% CI, 1.21-2.67; $\mathrm{P}=0.004)$, and an independent risk factor for lymph node and peritoneal metastasis. Immunohistochemical analysis revealed an intense CSF-1/CSF-1R expression in the cytoplasm of cancer cells in primary GC tissues. CSF-1 or CSF-1R expression positively correlated with vascular endothelial growth factor A (VEGFA) or Fms related tyrosine kinase 1 (FLT1) expression in GC tissues. Treatment with recombinant human $\mathrm{CSF}-1$ promoted
\end{abstract}

Correspondence to: Dr Yoshinaga Okugawa, Department of Gastrointestinal and Pediatric Surgery, Division of Reparative Medicine, Institute of Life Sciences, Mie University Graduate School of Medicine, 2-174 Edobashi, Tsu, Mie 514-8507, Japan

E-mail: yoshinaga.okugawa@gmail.com

Key words: colony-stimulating factor-1, colony-stimulating factor 1 receptor, gastric cancer, metastasis, prognosis proliferation, migration and anoikis resistance in a GC cell line. These effects were generally blocked by CSF-1R inhibition. On the whole, the findings of this study indicate that the CSF-1/CSF-1R axis may be a clinically useful prognostic and predictive biomarker for lymph node and peritoneal metastasis and a potential therapeutic target in GC.

\section{Introduction}

Despite recent advances in surgical techniques and treatment options, gastric cancer (GC) remains the third most common cause of cancer-related deaths worldwide (1). Approximately one-third of patients with GC have locally advanced cancer or metastatic disease at the time of diagnosis (2). Tumor-node-metastasis (TNM) staging is the most-recognized prognostic categorization for patients with GC; however, the prognosis for patients with the same TNM stage can differ (2), and the current staging system cannot conclusively predict patient outcomes. These findings highlight the critical need to discover prognostic biomarkers that can identify patients with $\mathrm{GC}$ who are at a high risk of developing disease recurrence and who may benefit from aggressive treatment. Furthermore, a better understanding of the molecular mechanisms underlying metastasis is crucial for the development of novel treatment strategies to improve the survival of patients with GC with metastasis.

Colony-stimulating factor-1 (CSF-1) is a critical hematopoietic growth factorinvolved in cell differentiation, proliferation and activation via binding to its receptor, c-fms/CSF-1 receptor (CSF-1R), expressed on microglia and macrophages $(3,4)$. Several studies have demonstrated that the overexpression of CSF-1 and CSF-1R correlates significantly with disease progression in various types of cancer $(5,6)$. Moreover, there is evidence to suggest that a CSF-1/CSF-1R autocrine loop contributes to tumor invasiveness and metastasis in breast, ovarian, lung and prostate cancer (7-14).

Previous studies by our group have demonstrated that several metastasis-associated genes and oncogenic cytokines are differentially expressed in advanced GC and can be used as biomarkers for the prognosis and prediction of metastasis 
in patients with GC (15-20). Although an increasing number of studies have established the function of the CSF-1/CSF-1R axis in other types of cancer, to date, and at least to the best of our knowledge, there have been no systematic investigations of the clinical significance of the CSF-1/CSF-1R axis and its potential functional role in the development of human GC. Thus, in this study, we investigated the expression profiles of CSF-1 and CSF-1R in a large cohort of GC tissue specimens to clarify their clinical significance as prognostic biomarkers in patients with $\mathrm{GC}$ and to assess the functional role of the CSF-1/CSF-1R axis in GC development.

\section{Materials and methods}

Patients and sample collection. Our study included 148 patients (118 males and 30 females) who underwent surgery for GC between 2000 and 2009 at Mie University Hospital, Tsu, Japan. The criteria for inclusion included the availability of cancer tissue samples with complete clinical data and isolated RNA of sufficient quality for real-time PCR. The mean patient age was 67 years (range, 18-90 years). No patient received chemotherapy or radiotherapy prior to surgery and no peri-operative mortalities were observed. The diagnosis of GC was confirmed for all 148 patients based on clinicopathological findings. All patients were classified according to the Japanese Classification of Gastric Carcinoma (21): A total of 21 patients had stage I disease, 40 had stage II, 43 had stage III and 44 had stage IV. Distal or total gastrectomy with D2 lymphadenectomy was performed in patients who underwent curative resection. Patients with liver, peritoneal, or distant metastasis underwent palliative gastrectomy with D1 lymphadenectomy. The mean follow-up time was 25 months (range, 1-79 months). During the study period, 68 patients died due to cancer-related causes. Tissue specimens were preserved immediately following surgical resection in RNAlater Stabilization Reagent (Qiagen, Chatsworth, CA, USA) and stored at $-80^{\circ} \mathrm{C}$ until RNA extraction. Written informed consent was obtained from each patient, and the study was approved by the Institutional Review Boards of Mie University (no. 2215).

Total RNA extraction, $c D N A$ synthesis and reverse transcription PCR (RT-PCR). RNAlater-preserved surgical specimens were homogenized with a Mixer Mill MM 300 homogenizer and tissue total RNA was isolated using RNeasy Mini kits (both from Qiagen) according to the manufacturer's instructions. cDNA was synthesized from $5 \mu \mathrm{g}$ total RNA with random hexamer primers and SuperScript III Reverse Transcriptase (Invitrogen, Carlsbad, CA, USA).

Real-time (quantitative) PCR and relative $m R N A$ expression analysis. Quantitative PCR (qPCR) following reverse transcription (RT-qPCR) analysis was performed using the StepOne Real-Time PCR System (Applied Biosystems, Foster City, CA, USA), as previously described (16). CSF-1, CSF-1R, vascular endothelial growth factor A (VEGFA), Fms related tyrosine kinase 1 (FLT1) and GAPDH mRNA expression levels were measured using Power SYBR-Green Master Mix (Life Technologies, Carlsbad, CA, USA). Primers for CSF-1, CSF-1R, VEGFA, FLT1 and GAPDH were designed using Primer3 software (Biology Workbench Version 3.2; San Diego
Supercomputer Center, University of California, San Diego, CA, USA). The following sequences were used: CSF-1 forward, GGAGACCTCGTGCCAAATTA and reverse, GGCATTGG GGGTGTTATCTC; CSF-1R forward, TGAGCAAGACCTG GACAAGGA and reverse, CCATTGGTCAACAGCACGTTA; VEGFA forward, TCTTCAAGCCATCCTGTGTG and reverse, CTATGTGCTGGCCTTGGTG; FLT1 forward, CTG AAGGAAGGGAGCTCGTC and reverse, TCCCAGATTATG CGTTTTCC; and GAPDH forward, GGAAGGTGAAGGTCG GAGTC and reverse, AATGAAGGGGTCATTGATGG. We performed 40 cycles of amplification under the following conditions: Denaturation at $95^{\circ} \mathrm{C}$ for $10 \mathrm{sec}$, annealing at $60^{\circ} \mathrm{C}$ for $10 \mathrm{sec}$ and elongation at $72^{\circ} \mathrm{C}$ for $20 \mathrm{sec}$. Following amplification, the products were subjected to a temperature gradient ranging from $68^{\circ} \mathrm{C}$ to $95^{\circ} \mathrm{C}$ at $0.2^{\circ} \mathrm{C} / \mathrm{sec}$ under continuous fluorescence monitoring to produce a melting curve of the products. Following proportional background adjustment, the fit-point method was used to determine the cycle in which the log-linear signal was distinguished from the background, and that cycle number was used as a crossing-point value. The expression levels of target transcripts and GAPDH were evaluated using Applied Biosystems StepOne Software v2.1, and quantified by the standard curve method, as previously described (22).

Immunohistochemical (IHC) analysis. IHC analyses of CSF-1 and CSF-1R were performed on the surgical specimens of primary GC using avidin-biotin-peroxidase methods (DakoCytomation, Carpinteria, CA, USA) on formalin-fixed, paraffin-embedded (FFPE) tissues sliced into sections of $2-3-\mu \mathrm{m}$ width. Following deparaffinization and dehydration, the specimens were brought to a boil in $10 \mathrm{mM}$ sodium citrate buffer for antigen unmasking. The specimens were then blocked and incubated with primary antibodies overnight at $4^{\circ} \mathrm{C}$. Antibodies were detected using Envision reagents (Envision kit/HRP; DakoCytomation, Glostrup, Denmark). The sections were incubated with primary goat polyclonal antibodies against CSF-1 (1:50; sc-1324; Santa Cruz Biotechnology, Santa Cruz, CA, USA) and CSF-1R (1:100; AP7604b; Abgent, San Diego, CA, USA) followed by labeled streptavidin-biotin (LASB2 kit/HRP), and then stained with 3,3'-diaminobenzidine (both from DakoCytomation, Carpinteria, CA, USA). The sections were counterstained with hematoxylin, dehydrated and mounted. Positive and negative control samples using spleen specimens were examined in parallel.

Immunofluorescence. Double immunofluorescence combined CSF-1 and CSF-1R. The sections were incubated with the primary antibodies for CSF-1 and for CSF-1R (1:100, described above) overnight at $4^{\circ} \mathrm{C}$. After washing the FFPE sections 5 times for 5 min with distilled water, Alexa Fluor ${ }^{\circledR} 488$ donkey anti-goat IgG (1:500, A-11055; Invitrogen, Renfrew, UK) and Dylight549 donkey anti-rabbit IgG (1:1,000, 611-742-127; Rockland, Limerick, PA, USA) as secondary antibodies, were incubated with the sections for $1 \mathrm{~h}$ at room temperature. Nuclear staining was carried out with 4',6'-diamidino-2-phenylindole dihydrochloride (DAPI; ProLong Gold Antifade Reagent with DAPI; Invitrogen). Confocal images were acquired using a IX71 inverted microscope with a DP70 digital camera system (Olympus, Center Valley, PA, USA). 
Cell lines. The human GC cell lines, MKN7 (intestinal type), MKN45 (diffuse type), MKN74 (intestinal type), KATO III (diffuse type) and NUGC3 (diffuse type) were obtained from the Cell Resource Center for Biomedical Research, Tohoku University, Sendai, Japan. These cell lines have been tested and authenticated at the Cell Resource Center for Biomedical Research, Tohoku University. The cells were maintained in RPMI-1640 medium supplemented with $10 \%$ fetal bovine serum and antibiotics at $37^{\circ} \mathrm{C}$ in a $5 \% \mathrm{CO}_{2}$ atmosphere.

Reagents recombinant human CSF-1 (rhCSF-1) was purchased from PeproTech (Rocky Hill, NJ, USA) and prepared according to the manufacturer's instructions. The c-fms/CSF-1R tyrosine kinase inhibitor $(14,23,24)$ was purchased from Santa Cruz Biotechnology and stored at $-20^{\circ} \mathrm{C}$ before use in vitro. To investigate the association between CSF-1 and CSF-1R, we used $5 \mu \mathrm{M}$ of CSF-1R inhibitor. The effects of rhCSF-1 (100 $\mathrm{ng} / \mathrm{ml}$ ) on the GC cell lines were compared to those on the untreated cells, cells treated with CSF-1R inhibitor or with cells pretreated with CSF-1R inhibitor for $2 \mathrm{~h}$ followed by treatment with rhCSF-1.

Cell proliferation assay. 3-(4,5-Dimethylthiazol-2-yl)-2,5diphenyltetrazolium bromide (MTT) assay (Sigma, St. Louis, MO, USA) was used to measure cell proliferation, as previously described $(16,25)$. Each independent experiment was performed three times in triplicate.

Cell migration scratch assays. Confluent GC cells were serum-deprived for $48 \mathrm{~h}$ and a wound was generated using a sterile 200- $\mu$ l pipette tip. The cells were pre-incubated with or without reagents (CSF-1, CSF-1R inhibitor), and wound closure was assessed using an Olympus IX71 microscope (Olympus) at x10 magnification, as previously described (25).

Anoikis assays. Anoikis assays were performed in 6-well Costar Ultra-Low Attachment multi-well plates (Corning Life Sciences, Corning, NY, USA). GC cell lines were resuspended at $5 \times 10^{5}$ cells $/ \mathrm{ml}$ in RPMI-1640 medium containing anoikis-enhancing or -inhibiting reagents (CSF-1, CSF-1R inhibitor). Following the induction of anoikis with $24 \mathrm{~h}$ of incubation, MTT assay was performed, as previously described (15).

Statistical analysis. Results are expressed as the median \pm interquartile range, and all statistical analyses were performed using Medcalc version 16.4.3 (Broekstraat 52, 9030; Mariakerke, Belgium). Differences between groups were estimated using the Chi-squared ( $\chi^{2}$ test), Mann-Whitney U test and one-way ANOVA, as appropriate. F-tests were used to assess the equality of variance for comparable groups, and Scheffé test was used as a post hoc test after ANOVA. Correlation coefficient tests were conducted for statistical correlations. The Spearman's correlation coefficient test was conducted for statistical correlations. For time-to-event analyses, survival estimates were calculated using Kaplan-Meier analysis, and groups were compared using the log-rank test. Receiver operating characteristic (ROC) curves were established to determine the cut-off values for the analysis of prognosis by Youden's index. Overall survival (OS) was measured from the date the patient underwent surgery to the date of death resulting from any cause, or to the last known follow-up for patients that were still alive. Disease-free survival (DFS) was measured from the date the patient underwent curative surgery to the date of disease recurrence, death from any cause (i.e., cancer-unrelated deaths were not censored), or the final contact with the patient. For assessment of the performance of prognostic markers for OS and DFS, the power calculations were based on the detection difference of 0.05 between favorable and unfavorable prognosis groups. We estimated that 126 and 88 patients (distributed equally between the 2 groups) were needed to achieve $80 \%$ power to substantiate $>25$ and $30 \%$ differences in prognostic and recurrent outcomes, respectively, at a significance level of 0.05 using a two-sided log-rank test. Our cohort of 148 patients with GC was therefore more than adequate. The Cox proportional hazards model was used to estimate hazard ratios (HRs) for death. Assumption of proportionality was confirmed for the Cox proportional hazards analyses by generating Kaplan-Meier survival curves (e.g., high vs. low expression groups) and by ensuring that the two curves did not intersect. Multivariate logistic regression models were used to predict factors influencing lymph node and peritoneal metastasis. Forced-entry regression was used to include these variables in all multivariable equations to analyze whether each of the predictors affected the outcome after adjusting for known confounders. All P-values were two-sided, and those $<0.05$ were considered to indicate statistically significant differences.

\section{Results}

High expression of CSF-1/CSF-1R is associated with disease progression in patients with $G C$. To determine whether the expression status of CSF-1 and CSF-1R has clinical significance in patients with $\mathrm{GC}$, we analyzed the association between the expression patterns and various clinicopathological factors (Table I). Expression profiling revealed that the elevated expression of CSF-1 was significantly associated with the presence of lymph node metastasis $(\mathrm{P}=0.03)$, peritoneal metastasis $(\mathrm{P}=0.03)$ and the progression of TNM stage classification $(\mathrm{P}=0.003)$ in patients with $\mathrm{GC}$. Furthermore, the overexpression of CSF-1R was significantly associated with the same factors for disease progression and metastasis formation, such as an advanced $\mathrm{T}$ category $(\mathrm{P}=0.002)$, lymph node metastasis $(\mathrm{P}=0.02)$, peritoneal metastasis $(\mathrm{P}=0.02)$ and the progression of TNM stage classification $(\mathrm{P}=0.005)$. Although the median values of both CSF-1 and CSF-1R in patients with stage IV disease were decreased compared with their median values in patients with stage III disease, scattergram analyses revealed no significant differences between stage III and stage IV GC as regards both CSF-1 and CSF-1R expression (Fig. 1A and B). Indeed, patients with stage IV harbored various type of distant metastasis, including hepatic metastasis, distant lymph node metastasis and peritoneal metastasis, and the background of these patients may be influenced by these findings in this study.

Highexpression ofCSF-1/CSF-1R is associated with recurrence and a poor outcome in patients with $G C$. We then performed time-to-event analyses to evaluate the prognostic relevance of 
Table I. Clinicopathological variables and CSF-1/CSF-1R expression in patients with gastric cancer.

\begin{tabular}{|c|c|c|c|c|c|}
\hline Variable & $\mathrm{n}$ & $\begin{array}{c}\text { CSF-1 } \\
\text { expression }\end{array}$ & P-value & $\begin{array}{c}\text { CSF-1R } \\
\text { expression }\end{array}$ & P-value \\
\hline \multicolumn{6}{|l|}{ Sex } \\
\hline Male & 118 & $16.7 \pm 26.6$ & \multirow[t]{2}{*}{0.76} & $0.41 \pm 0.99$ & \multirow[t]{2}{*}{0.92} \\
\hline Female & 30 & $20.3 \pm 25.4$ & & $0.4 \pm 1.03$ & \\
\hline \multicolumn{6}{|l|}{ Age (years) } \\
\hline$<70^{\mathrm{a}}$ & 72 & $17.7 \pm 27.5$ & \multirow[t]{2}{*}{0.64} & $0.53 \pm 1.2$ & \multirow[t]{2}{*}{0.42} \\
\hline$\geq 70$ & 76 & $16.8 \pm 26.2$ & & $0.34 \pm 0.76$ & \\
\hline \multicolumn{6}{|l|}{ Location } \\
\hline Proximal & 64 & $16.7 \pm 21.0$ & \multirow[t]{2}{*}{0.74} & $0.38 \pm 0.89$ & \multirow[t]{2}{*}{0.63} \\
\hline Distal & 84 & $18.8 \pm 27.7$ & & $0.43 \pm 1.26$ & \\
\hline \multicolumn{6}{|l|}{ Histological type } \\
\hline Intestinal type & 73 & $20.3 \pm 29.4$ & \multirow[t]{2}{*}{0.46} & $0.44 \pm 1.33$ & \multirow[t]{2}{*}{0.34} \\
\hline Diffuse type & 75 & $17.2 \pm 20.1$ & & $0.38 \pm 0.88$ & \\
\hline \multicolumn{6}{|l|}{ Tumor Size } \\
\hline$\geq 5.5 \mathrm{~cm}^{\mathrm{b}}$ & 74 & $16.7 \pm 29.7$ & \multirow[t]{2}{*}{0.45} & $0.43 \pm 1.24$ & \multirow[t]{2}{*}{0.81} \\
\hline$<5.5 \mathrm{~cm}$ & 74 & $19.2 \pm 22.2$ & & $0.38 \pm 0.99$ & \\
\hline \multicolumn{6}{|c|}{ Pathological T category } \\
\hline $\mathrm{pT} 1 / 2$ & 50 & $14.5 \pm 23.2$ & \multirow[t]{2}{*}{0.08} & $0.17 \pm 0.53$ & \multirow[t]{2}{*}{$0.002^{c}$} \\
\hline $\mathrm{pT} 3 / 4$ & 98 & $18.5 \pm 27.7$ & & $0.52 \pm 1.28$ & \\
\hline \multicolumn{6}{|c|}{ Lymph node metastasis } \\
\hline No & 42 & $12.2 \pm 21.7$ & \multirow[t]{2}{*}{$\mathbf{0 . 0 3}{ }^{\mathrm{c}}$} & $0.25 \pm 0.47$ & \multirow[t]{2}{*}{$0.02^{\mathrm{c}}$} \\
\hline N1 & 106 & $18.8 \pm 26.8$ & & $0.46 \pm 1.28$ & \\
\hline \multicolumn{6}{|c|}{ Peritoneal metastasis } \\
\hline $\mathrm{P} 0$ & 122 & $16.1 \pm 23.9$ & \multirow[t]{2}{*}{$\mathbf{0 . 0 3}{ }^{\mathrm{c}}$} & $0.38 \pm 0.91$ & \multirow[t]{2}{*}{$\mathbf{0 . 0 2 ^ { c }}$} \\
\hline $\mathrm{P} 1$ & 26 & $25.2 \pm 48.1$ & & $0.54 \pm 1.75$ & \\
\hline \multicolumn{6}{|c|}{ Distant metastasis } \\
\hline M0 & 104 & $16.7 \pm 25.2$ & \multirow[t]{2}{*}{0.1} & $0.38 \pm 1.06$ & \multirow[t]{2}{*}{0.41} \\
\hline M1 & 44 & $19.4 \pm 29.8$ & & $0.46 \pm 0.88$ & \\
\hline \multicolumn{6}{|c|}{ UICC TNM classification } \\
\hline Stage I & 21 & $18.5 \pm 26.6$ & \multirow[t]{4}{*}{$\mathbf{0 . 0 0 3}{ }^{\mathrm{c}}$} & $0.17 \pm 0.61$ & \multirow[t]{4}{*}{$0.005^{\mathrm{c}}$} \\
\hline Stage II & 40 & $9.58 \pm 13.4$ & & $0.24 \pm 0.43$ & \\
\hline Stage III & 43 & $24.6 \pm 26.9$ & & $0.91 \pm 1.57$ & \\
\hline Stage IV & 44 & $19.4 \pm 29.8$ & & $0.46 \pm 0.88$ & \\
\hline
\end{tabular}

${ }^{a}$ The median age at surgery for this cohort was 70 years; ${ }^{b}$ the median size of the primary tumor for this cohort was $5.5 \mathrm{~cm}$; ${ }^{\mathrm{c} b o l d}$ numbers indicate statistical significance $(\mathrm{P}<0.05)$. All of these data were in this table were analyzed using Mann-Whitney $U$ test.

CSF-1 and CSF-1R expression for OS and DSF. The expression cut-off thresholds for CSF-1 and CSF-1R for these analyses were determined from ROC curves with Youden's index. Of note, the high expression of CSF-1 and CSF-1R was significantly associated with a poor prognosis, compared with the low expression groups, for both OS [CSF-1, $\mathrm{P}=0.037$; CSF-1R, $\mathrm{P}=0.016$; log-rank test (Fig. $1 \mathrm{C}$ and $\mathrm{D})]$ and DFS [CSF-1, $\mathrm{P}<0.001$; CSF-1R, $\mathrm{P}<0.001$; log-rank test (Fig. 1E and $\mathrm{F}$ )]. Of note, both the CSF-1 and CSF-1R expression levels did not correlate significantly with well-established tumor markers, such as CEA and CA19-9 in this cohort (Fig. 1G). Furthermore, the analysis of the prognostic value of these markers revealed that a high expression of both CSF-1 and
CSF-1R in the same tissue (co-expression) was significantly associsated with a poor prognosis, compared with patients with a low co-expression, for both $\mathrm{OS}(\mathrm{P}=0.039$, log-rank test $)$ and DFS ( $\mathrm{P}<0.001$, log-rank test) (Fig. $1 \mathrm{H}$ and $\mathrm{I})$. To determine the value of high CSF-1/CSF-1R co-expression as a predictive biomarker for disease recurrence and the prognosis of patients with GC, we performed multivariate Cox regression analysis. The data revealed that a high CSF-1/CSF-1R co-expression was an independent prognostic factor for OS [HR, 1.38; $95 \%$ confidence interval $(\mathrm{CI}), 1.02-1.88 ; \mathrm{P}=0.038$ ] in patients with GC (Table IIA). In addition, an advanced $\mathrm{T}$ category (HR, 4.01; 95\% CI, 1.75-9.21; $\mathrm{P}=0.001)$, the presence of lymph node metastasis (HR, 4.85; 95\% CI, 1.57-14.9; $\mathrm{P}=0.006)$ and 
A

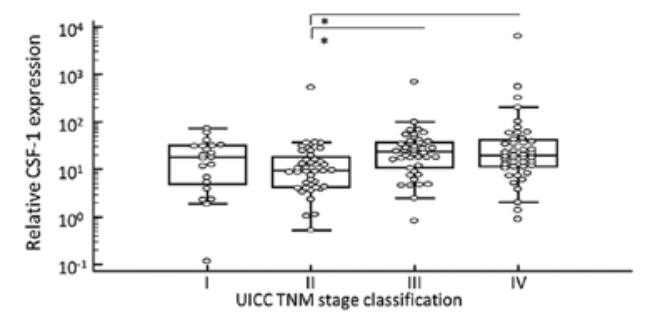

C

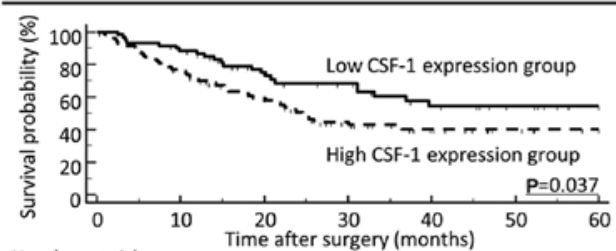

Number at risk

$\begin{array}{lllllll}\text { Low CSF-1 }_{64} \text { expression group } & \\ 52 & 35 & 27 & 18 & 13 & 0\end{array}$

$\begin{array}{rllllll}\text { High CSF-1 } & \text { expression group } \\ 84 & 63 & 24 & 13 & 6 & 0\end{array}$

E

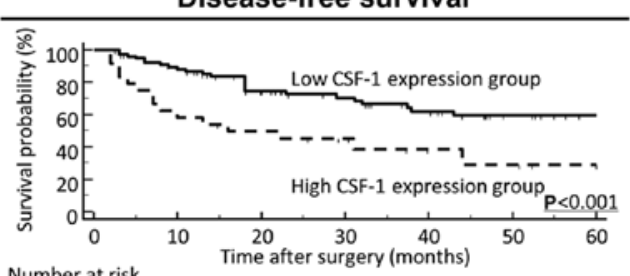

Number at risk

Low CSF-1 expression group $_{78} \quad \begin{array}{llllll}64 & 36 & 27 & 17 & 0\end{array}$

$\begin{array}{rlllll}\text { High } \mathrm{CSF}_{23} \text { expression group } & & & & & \\ 13 & 10 & 3 & 2 & 0\end{array}$

G
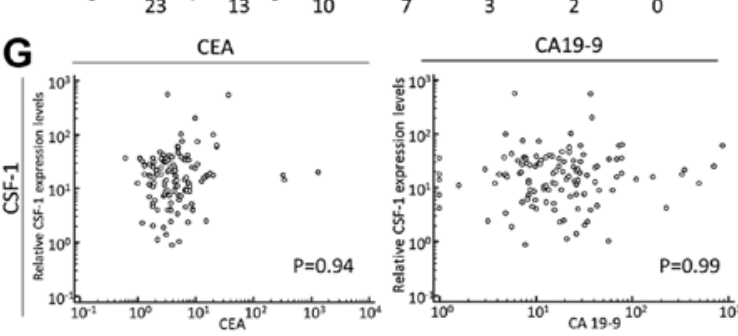

$\mathbf{H}$

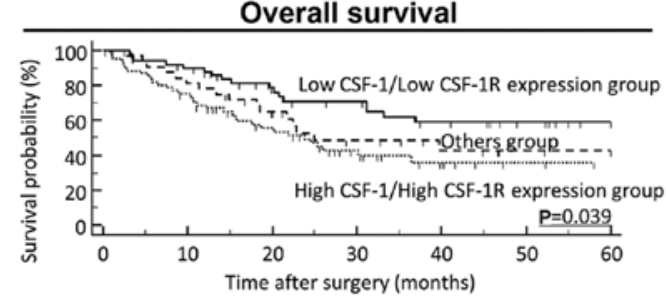

Number at risk

\begin{tabular}{|c|c|c|c|c|c|c|}
\hline \multicolumn{7}{|c|}{ Low CSF-1/Low CSF-1P } \\
\hline 53 & 44 & 31 & 25 & 18 & 13 & 0 \\
\hline \multicolumn{7}{|c|}{ Others group } \\
\hline 33 & 26 & 18 & 11 & 7 & 4 & 0 \\
\hline \multicolumn{7}{|c|}{ High CSF-1/High CSF-1R expression group } \\
\hline 62 & 45 & 28 & 15 & 6 & 2 & 0 \\
\hline
\end{tabular}

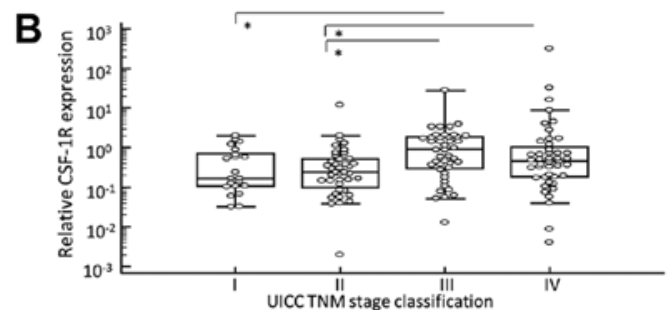

D Overall survival

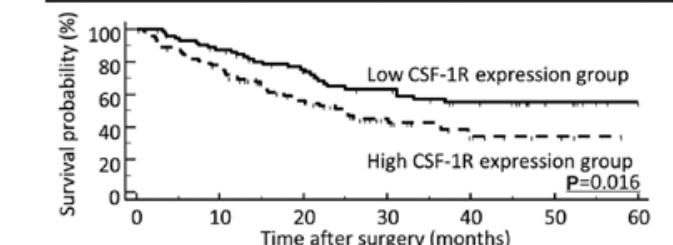

Number at risk Low CSF-1R expression group

$\begin{array}{llllll}\text { High CSF-1R expression group } & & & & \\ 73 & 17 & 6 & 2 & 0\end{array}$

$\mathbf{F}$

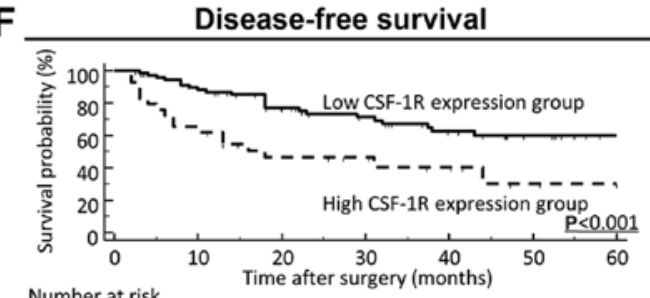

Number at risk

Low CSF-1R expression group

High CSF-1R expression group

35

25

0

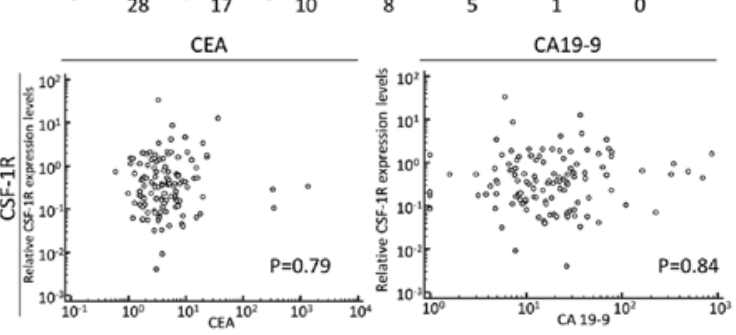

I

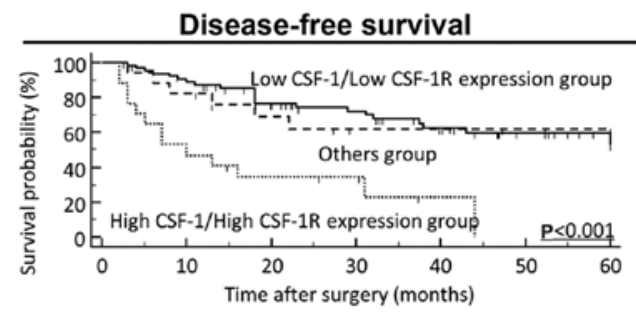

Number at risk

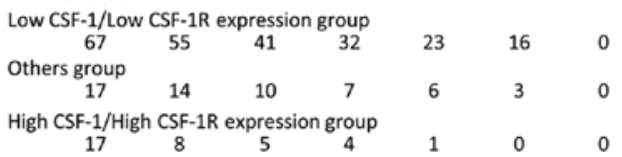

Figure 1. Prognostic value of the colony-stimulating-factor-1(CSF-1)/CSF-1 receptor (CSF-1R) expression status on the overall survival (OS) and disease-free survival (DFS) of patients with gastric cancer (GC). (A and B) Scattergrams of the CSF-1 and CSF-1R expression status according to the Japanese Classification of Gastric Carcinoma in GC patients. Although median values of both (A) CSF-1 and (B) CSF-1R in patients with stage IV disease were decreased compared with their median values in patients with stage III disease, scattergram analyses revealed no significant difference between stage III and stage IV GC as regards both CSF-1 and CSF-1R expression. (C and D) Kaplan-Meier survival curves for the overall survival of patients with GC based on the expression of (C) CSF-1 and (D) CSF-1R. The OS rate of patients with GC with a high tumor expression of CSF-1 or CSF-1R was significantly lower than that of patients with a low tumor expression of CSF-1 or CSF-1R (CSF-1, $\mathrm{P}=0.037$; CSF-1R, $\mathrm{P}=0.016$; log-rank test). (E and F) Kaplan-Meier survival curves for the DFS of patients with GC based on the expression of (E) CSF-1 and (F) CSF-1R. It should be noted here that for disease-free survival, patients with non-curative intent (stage IV) were not included; thus, the patient numbers differ from those for OS. The DFS rate of patients with GC with a high tumor expression of CSF-1 or CSF-1R was significantly lower than that of patients with a low tumor expression of CSF-1 or CSF-1R (CSF-1, P<0.001; CSF-1R, P<0.001; log-rank test). (G) Correlation between pre-operative tumor marker levels and CSF-1 and CSF-1R expression levels in primary tumors. Both the CSF-1 (left panel) and CSF-1R (right panel) expression levels did not significantly correlate with well-established tumor markers, such as CEA and CA19-9 in this study cohort. (H) Kaplan-Meier survival curves for (H) OS and (I) DFS of patients with GC based on the co-expression of CSF-1 and CSF-1R. The 'Others group' included patients with a high CSF-1 expression or high CSF-1R expression. Co-expression status of CSF-1 and CSF-1R was significantly associated with a poor OS and DFS of patients with GC (OS, P=0.039; DFS, P<0.001; log-rank test). All statistical tests were two-sided. 
Table II. Multivariate analysis for predictors of overall survival and disease-free survival.

A, Multivariate analysis for predictors of overall survival

\begin{tabular}{|c|c|c|c|c|c|c|}
\hline \multirow[b]{2}{*}{ Variables } & \multicolumn{3}{|c|}{ Univariate } & \multicolumn{3}{|c|}{ Multivariate } \\
\hline & HR & $95 \% \mathrm{CI}$ & P-value & HR & $95 \% \mathrm{CI}$ & P-value \\
\hline Sex (male) & 0.78 & $0.44-1.38$ & 0.39 & 1.3 & $0.78-2.17$ & 0.32 \\
\hline Age $(\geq 70 \text { years })^{\mathrm{a}}$ & 1.16 & $0.72-1.87$ & 0.54 & 0.5 & $0.26-0.96$ & $\mathbf{0 . 0 3 8}{ }^{\mathrm{d}}$ \\
\hline Histological type (intestinal type) & 0.97 & $0.6-1.56$ & 0.89 & 0.98 & $0.59-1.62$ & 0.94 \\
\hline Tumor size $(\geq 5.5 \mathrm{~cm})^{\mathrm{b}}$ & 1.53 & $0.95-2.48$ & 0.08 & 1.44 & $0.88-2.36$ & 0.15 \\
\hline T classification (pT3/4) & 3.32 & $1.8-6.11$ & $<0.001^{\mathrm{d}}$ & 1.54 & $0.58-4.07$ & 0.39 \\
\hline Vessel involvement (present) & 3.96 & $1.59-9.86$ & $\mathbf{0 . 0 0 3}{ }^{\mathrm{d}}$ & 5.95 & $1.5-23.6$ & $0.011^{\mathrm{d}}$ \\
\hline Lymphatic vessel involvement (present) & 2.03 & $0.64-6.48$ & 0.23 & 0.19 & $0.03-1.15$ & 0.07 \\
\hline Lymph node metastasis (present) & 3.77 & $1.86-7.62$ & $<0.001^{\text {d }}$ & 1.99 & $0.78-5.13$ & 0.15 \\
\hline UICC TNM stage classification (stage III/IV) & 4.92 & $2.67-9.07$ & $<0.001^{\mathrm{d}}$ & 2.26 & $0.74-6.9$ & 0.15 \\
\hline High CSF-1/high CSF-1R expression ${ }^{c}$ & 1.44 & $1.08-1.9$ & $0.012^{\mathrm{d}}$ & 1.38 & $1.02-1.88$ & $\mathbf{0 . 0 3 8}{ }^{\mathrm{d}}$ \\
\hline
\end{tabular}

B, Multivariate analysis for predictors of disease-free survival

\begin{tabular}{|c|c|c|c|c|c|c|}
\hline \multirow[b]{2}{*}{ Variables } & \multicolumn{3}{|c|}{ Univariate } & \multicolumn{3}{|c|}{ Multivariate } \\
\hline & HR & $95 \% \mathrm{CI}$ & P-value & HR & $95 \% \mathrm{CI}$ & P-value \\
\hline Sex (male) & 1.47 & $0.58-3.78$ & 0.42 & 0.49 & $0.17-1.44$ & 0.49 \\
\hline Age $(\geq 70 \text { years })^{a}$ & 1.17 & $0.63-2.18$ & 0.62 & 1.1 & $0.57-2.15$ & 0.77 \\
\hline Histological type (intestinal type) & 1.3 & $0.7-2.42$ & 0.4 & 1.54 & $0.8-2.96$ & 0.19 \\
\hline Tumor size $(\geq 5.5 \mathrm{~cm})^{\mathrm{b}}$ & 0.96 & $0.52-1.78$ & 0.89 & 0.64 & $0.33-1.24$ & 0.19 \\
\hline T classification (pT3/4) & 4.48 & $2.06-9.75$ & $<0.001^{\mathrm{d}}$ & 4.01 & $1.75-9.21$ & $0.0011^{\mathrm{d}}$ \\
\hline Vessel involvement (present) & 2.56 & $1.07-6.12$ & $\mathbf{0 . 0 3 5} 5^{\mathrm{d}}$ & 2.11 & $0.59-7.5$ & 0.25 \\
\hline Lymphatic vessel involvement (present) & 1.91 & $0.59-6.21$ & 0.28 & 0.6 & $0.11-3.3$ & 0.55 \\
\hline Lymph node metastasis (present) & 7.37 & $2.61-20.8$ & $<0.001^{\mathrm{d}}$ & 4.85 & $1.57-14.9$ & $\mathbf{0 . 0 0 6}^{\mathrm{d}}$ \\
\hline High CSF-1/high CSF-1R expressionc & 2.08 & $1.44-3.01$ & $<0.001^{\mathrm{d}}$ & 1.79 & $1.21-2.67$ & $0.004^{\mathrm{d}}$ \\
\hline
\end{tabular}

${ }^{a}$ The median age at surgery was 70 years; ${ }^{b}$ the median size of the primary tumor was $5.5 \mathrm{~cm}$; ${ }^{\mathrm{c}} \mathrm{Cut}$-off thresholds for CSF-1 and CSF-1R expression were determined by ROC analysis with Youden's index; dbold numbers indicate statistical significance $(\mathrm{P}<0.05)$. HR, hazard ratio.

a high CSF-1/CSF-1R co-expression (HR, 1.79; 95\% CI, 1.21-2.67; $\mathrm{P}=0.004)$ were independent prognostic factors for DFS in patients with GC (Table IIB).

To further assess the clinical significance of the CSF-1/CSF-1R expression status in GC tissues, we analyzed the association of high CSF-1/CSF-1R co-expression with various clinicopathological factors in patients with GC (Table III). A high co-expression was significantly associated with a younger age $(\mathrm{P}=0.02)$, an advanced $\mathrm{T}$ category $(\mathrm{P}=0.047)$, the presence of lymph node metastasis $(\mathrm{P}=0.017)$ and with the progression of TNM stage classification $(\mathrm{P}=0.013)$.

A high co-expression of CSF-1/CSF-1R is a predictive factor for the presence of lymph node and peritoneal metastasis in patients with $G C$. We found that the overexpression of the CSF-1/CSF-1R axis was intimately associated with the presence of lymph node and peritoneal metastasis in patients with GC (Tables I and III). Based on these findings, we performed a multivariate logistic analysis to determine the clinical significance of CSF-1/CSF-1R co-expression as a predictive biomarker for metastasis (Table IV). Notably, a high CSF-1/CSF-1R co-expression was shown to be an independent predictive factor for both lymph node metastasis [odds ratio (OR), 2.07; 95\% $\mathrm{CI}, 1.29-3.33 ; \mathrm{P}=0.003$ ] and peritoneal metastasis (OR, 2.27; 95\% CI, 1.1-4.69; $\mathrm{P}=0.026)$.

CSF-1 and CSF-1R are highly expressed in cancer cells compared with cancer stromal cells or normal mucosa in GC tissues. To confirm the pathological expression patterns of CSF-1 and CSF-1R in the clinical specimens, we performed IHC analysis of 10 primary GC tissues. Notably, both CSF-1 and CSF-1R expression levels were mainly expressed in the cellular membrane of GC cells, and little expression was detected in the cancer stroma or adjacent normal mucosa (Fig. 2). From these results, we concluded that CSF-1 and CSF-1R were overexpressed in GC cells compared with normal mucosa, suggesting that this signaling axis may play a role in disease progression. Therefore, we focused the remainder of our study on assessing the biological function of the CSF-1/CSF-1R axis in gastric neoplasia. 
Table III. Clinicopathological variables and CSF-1/CSF-1R expression in gastric cancer patients.

\begin{tabular}{|c|c|c|c|c|c|}
\hline Variable & $\mathrm{n}$ & $\begin{array}{l}\text { High CSF-1/high CSF-1R } \\
\qquad(\mathrm{n}=62)\end{array}$ & $\begin{array}{l}\text { Others }^{\mathrm{b}} \\
(\mathrm{n}=33)\end{array}$ & $\begin{array}{l}\text { Low CSF-1/low CSF-1R } \\
\qquad(\mathrm{n}=53)\end{array}$ & P-value \\
\hline \multicolumn{6}{|l|}{ Sex } \\
\hline Male & 118 & 48 & 27 & 43 & \multirow[t]{2}{*}{$0.61^{\mathrm{d}}$} \\
\hline Female & 30 & 14 & 6 & 10 & \\
\hline \multicolumn{6}{|l|}{ Age (years) } \\
\hline$<70^{\mathrm{a}}$ & 72 & 37 & 10 & 25 & \multirow[t]{2}{*}{$\mathbf{0 . 0 2} 2^{\mathrm{d}, \mathrm{e}}$} \\
\hline$\geq 70$ & 76 & 25 & 23 & 28 & \\
\hline \multicolumn{6}{|l|}{ Location } \\
\hline Proximal & 64 & 25 & 15 & 24 & \multirow[t]{2}{*}{$0.59^{\mathrm{d}}$} \\
\hline Distal & 84 & 37 & 18 & 29 & \\
\hline \multicolumn{6}{|l|}{ Histological type } \\
\hline Intestinal type & 73 & 34 & 12 & 27 & \multirow[t]{2}{*}{$0.63^{\mathrm{d}}$} \\
\hline Diffuse type & 75 & 28 & 21 & 26 & \\
\hline \multicolumn{6}{|l|}{ Tumor size } \\
\hline$\geq 5.5 \mathrm{~cm}^{\mathrm{c}}$ & 74 & 31 & 16 & 27 & \multirow[t]{2}{*}{$0.93^{\mathrm{d}}$} \\
\hline$<5.5 \mathrm{~cm}$ & 74 & 31 & 17 & 26 & \\
\hline \multicolumn{6}{|c|}{ Pathological T category } \\
\hline $\mathrm{pT} 1 / 2$ & 50 & 15 & 13 & 22 & \multirow[t]{2}{*}{$\mathbf{0 . 0 4 7 ^ { \mathrm { d } , \mathrm { e } }}$} \\
\hline $\mathrm{pT} 3 / 4$ & 98 & 47 & 20 & 31 & \\
\hline \multicolumn{6}{|c|}{ Lymph node metastasis } \\
\hline No & 42 & 12 & 9 & 21 & \multirow[t]{2}{*}{$0.017^{\mathrm{d}, \mathrm{e}}$} \\
\hline N1 & 106 & 50 & 24 & 32 & \\
\hline \multicolumn{6}{|c|}{ Peritoneal metastasis } \\
\hline P0 & 122 & 48 & 26 & 48 & \multirow[t]{2}{*}{$0.068^{\mathrm{d}}$} \\
\hline P1 & 26 & 14 & 7 & 5 & \\
\hline \multicolumn{6}{|c|}{ Distant metastasis } \\
\hline M0 & 104 & 41 & 23 & 40 & \multirow[t]{2}{*}{$0.28^{\mathrm{d}}$} \\
\hline M1 & 44 & 21 & 10 & 13 & \\
\hline \multicolumn{6}{|c|}{ UICC TNM classification } \\
\hline Stage I & 21 & 8 & 5 & 8 & \multirow[t]{4}{*}{$0.013^{\mathrm{d}, \mathrm{e}}$} \\
\hline Stage II & 40 & 8 & 9 & 23 & \\
\hline Stage III & 43 & 25 & 9 & 9 & \\
\hline Stage IV & 44 & 21 & 10 & 13 & \\
\hline
\end{tabular}

${ }^{a}$ The median age at surgery for this cohort was 70 years; ${ }^{\text {th }}$ the patients with a high CSF-1 expression or a high CSF-1R expression in gastric cancer tissues were assigned to the group named 'Others'; 'the median size of the primary tumor for this cohort was $5.5 \mathrm{~cm}$; ${ }^{\mathrm{d}} \mathrm{Chi}$-squared test for trend; 'bold numbers indicate statistical significance $(\mathrm{P}<0.05)$.

Inhibition of the CSF-1/CSF-1R axis suppresses GC cell proliferation, migration and anoikis resistance. As described above, we found that the overexpression of CSF-1 and CSF-1R was associated with disease progression, metastasis, DFS and $\mathrm{OS}$ in patients with GC, and this prompted us to examine the functional role of this axis in the pathogenesis of GC. For these analyses, we incubated human GC cell lines in vitro with or without rhCSF-1 and/or a CSF-1R signaling inhibitor. First, CSF-1 and CSF-1R expression in the MKN7, MKN45, MKN74, KATO III and NUGC3 human GC cell lines was assessed by RT-qPCR (Fig. 3A). Furthermore, to clarify the localization of CSF-1 and CSF-1R expression in GC cells, we carried out fluorescent immunocytochemistry using the NUGC3 cells as both CSF-1 and CSF-1R were highly co-expressed in these cells (Fig. 3A). Fluorescent immunocytochemistry clearly revealed the co-expression of CSF-1 and CSF-1R in the cellular membrane of the same GC cell, and successfully verified the finding of gene expression in the GC cell line (Fig. 3B). Based on the findings of RT-qPCR, the MKN74 cells were subsequently selected for use in the following experiments, since they lacked CSF-1 expression and exhibited the highest expression of CSF-1R.

The cells were pre-incubated with or without the CSF-1R inhibitor and then exposed to CSF-1. After $72 \mathrm{~h}$, the effects on 
Table IV. Multivariate analysis for lymph node metastasis and peritoneal metastasis.

A, Multivariate analysis for lymph node metastasis.

\begin{tabular}{|c|c|c|c|c|c|c|}
\hline \multirow[b]{2}{*}{ Variables } & \multicolumn{3}{|c|}{ Univariate } & \multicolumn{3}{|c|}{ Multivariate } \\
\hline & OR & $95 \% \mathrm{CI}$ & P-value & OR & $95 \% \mathrm{CI}$ & P-value \\
\hline Sex (male) & 1.34 & $0.57-3,18$ & 0.5 & 1.63 & $0.59-4.51$ & 0.34 \\
\hline $\operatorname{Age}(\geq 70 \text { years })^{\mathrm{a}}$ & 1.61 & $0.78-3.31$ & 0.19 & 1.62 & $0.69-3.77$ & 0.26 \\
\hline Histological type (intestinal type) & 1.36 & $066-2.78$ & 0.41 & 1.6 & $0.67-3.78$ & 0.29 \\
\hline Tumor size $(\geq 5.5 \mathrm{~cm})^{\mathrm{b}}$ & 1.14 & $0.56-2.33$ & 0.71 & 1.15 & $0.48-2.74$ & 0.76 \\
\hline T classification (pT3/4) & 2.66 & $1.27-5.57$ & $\mathbf{0 . 0 1}{ }^{\mathrm{d}}$ & 2.18 & $0.91-5.27$ & 0.08 \\
\hline Vessel involvement (present) & 6.52 & $2.66-16.0$ & $<0.001^{\mathrm{d}}$ & 4.45 & $1.44-13.8$ & $\mathbf{0 . 0 1}{ }^{\mathrm{d}}$ \\
\hline Lymphatic vessel involvement (present) & 8.08 & $2.03-32.2$ & $\mathbf{0 . 0 0 3}^{\mathrm{d}}$ & 2.26 & $0.41-12.4$ & 0.35 \\
\hline High CSF-1/high CSF-1R expression ${ }^{c}$ & 1.93 & $1.27-2.93$ & $0.002^{\mathrm{d}}$ & 2.07 & $1.29-3.33$ & $\mathbf{0 . 0 0 3}^{\mathrm{d}}$ \\
\hline
\end{tabular}

$\mathrm{B}$, Multivariate analysis for peritoneal metastasis

\begin{tabular}{|c|c|c|c|c|c|c|}
\hline \multirow[b]{2}{*}{ Variables } & \multicolumn{3}{|c|}{ Univariate } & \multicolumn{3}{|c|}{ Multivariate } \\
\hline & OR & $95 \% \mathrm{CI}$ & P-value & OR & $95 \% \mathrm{CI}$ & P-value \\
\hline Sex (male) & 0.25 & $0.1-0.63$ & $\mathbf{0 . 0 0 3} 3^{\mathrm{d}}$ & 0.21 & $0.07-0.63$ & $0.0066^{\mathrm{d}}$ \\
\hline Age $(\geq 70 \text { years })^{\mathrm{a}}$ & 1.13 & $0.48-2.64$ & 0.78 & 1.07 & $0.39-2.9$ & 0.9 \\
\hline Histological type (intestinal type) & 0.45 & $0.19-1.09$ & 0.08 & 0.51 & $0.18-1.44$ & 0.2 \\
\hline Tumor size $(\geq 5.5 \mathrm{~cm})^{\mathrm{b}}$ & 2.65 & $1.07-6.56$ & $\mathbf{0 . 0 3 5} 5^{\mathrm{d}}$ & 2.19 & $0.76-6.28$ & 0.14 \\
\hline T classification (pT3/4) & 4.8 & $1.37-16.9$ & $0.0144^{\mathrm{d}}$ & 3.37 & $0.78-4.5$ & 0.1 \\
\hline Vessel involvement (present) & - & - & 0.99 & - & - & 0.99 \\
\hline Lymphatic vessel involvement (present) & - & - & 0.99 & - & - & 1 \\
\hline Lymph node metastasis (present) & 2.49 & $0.8-7.72$ & 0.11 & 1.92 & $0.49-7.55$ & 0.35 \\
\hline High CSF-1/high CSF-1R expression ${ }^{c}$ & 2.38 & $1.26-4.49$ & $\mathbf{0 . 0 0 7} 7^{\mathrm{d}}$ & 2.27 & $1.1-4.69$ & $0.026^{\mathrm{d}}$ \\
\hline
\end{tabular}

${ }^{\mathrm{a}}$ The median age at surgery was 70 years; ${ }^{\mathrm{b}}$ the median size of the primary tumor was $5.5 \mathrm{~cm}$; ${ }^{\mathrm{c}}$ cut-off thresholds for CSF- 1 and CSF-1R expression were determined by ROC analysis with Youden's index; d bold numbers indicate statistical significance $(\mathrm{P}<0.05)$.

cell proliferation were analyzed by MTT assay. We observed a significant increase in the proliferation of rhCSF-1-treated GC cells compared with the untreated cells, and pre-incubation with the CSF-1R inhibitor suppressed the effects of rhCSF-1, confirming that the CSF-1-stimulated proliferation of GC cells occurred via CSF-1R (Fig. 3C and D).

Anoikis is a form of apoptosis induced by the loss of cell adhesion (26), and resistance to anoikis is considered a necessary property of cancer cells during dissemination and metastasis (27). As our data revealed that the overexpression of CSF-1 and CSF-1R was an independent risk factor for lymph node and peritoneal metastasis, we hypothesized that a novel function of the CSF-1/CSF-1R axis may be to support resistance to anoikis in the advanced stages of GC. To determine whether the inhibition of the CSF-1/CSF-1R axis induces anoikis resistance, we pre-incubated GC cells with or without the CSF-1R inhibitor and then exposed them to rhCSF-1 in anchorage-independent growth cultures using ultra-low attachment plates. We found that rhCSF-1 treatment alone caused an increase in the number of floating viable GC cells to a level significantly higher than that observed in the control cultures. The effect of CSF-1 was blocked in GC cells pretreated with the CSF-1R inhibitor (Fig. 3E). Furthermore, in wound-healing assays, we observed an increase in the migration of rhCSF-1-treated cells compared with untreated cells, and here as well, pretreatment with the CSF-1R inhibitor suppressed the pro-migratory effects of CSF-1 in this cell line (Fig. 3F).

Expression levels of VEGFA and FLT1 in cancerous tissues were positively associated with $C S F-1$ and $C S F-1 R$ expression and are associated with a poor prognosis of patients with $G C$. Finally, to clarify the prognostic impact of angiogenetic factors and its correlation with CSF-1 and CSF1R expression in GC tissues, we quantified VEGFA and its receptor (FLT1) expression in GC tissues. A high expression of VEGFA and FLT1 was significantly associated with a poor prognosis, compared with the low expression groups, for OS [VEGFA, $\mathrm{P}=0.0052$; FLT1, $\mathrm{P}=0.0097$; log-rank test (Fig. 4A, upper panels)]. A high expression of VEGFA and FLT1 was also found to be associated with a poor prognosis, compared with the low expression groups, for DFS [VEGFA, P=0.062; FLT1, $\mathrm{P}=0.11$; log-rank test (Fig. 4A, lower panels)]. Furthermore, the CSF-1 or CSF-1R expression levels positively correlated with the VEGFA or FLT1 expression levels in GC tissues (CSF-1 
A

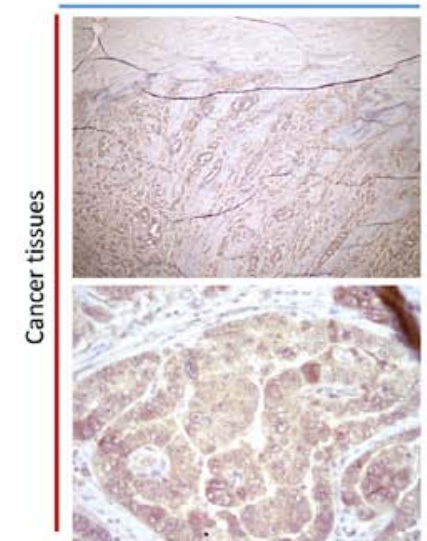

B
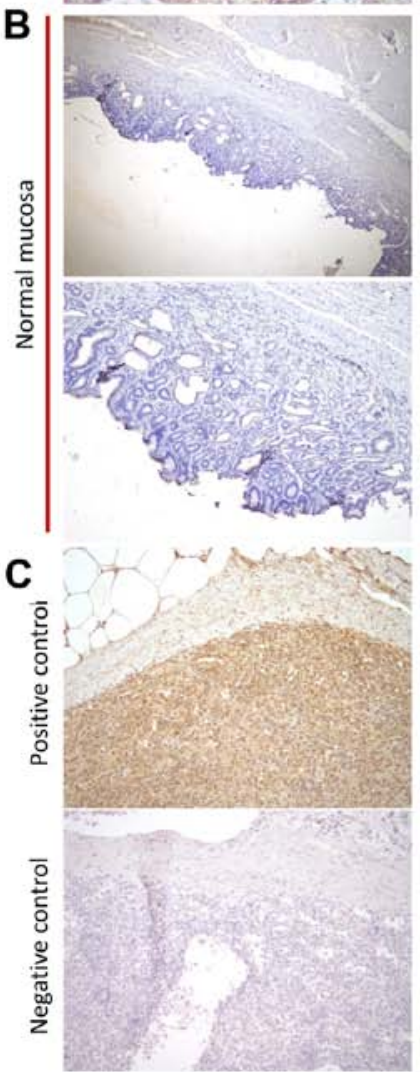

CSF-1R
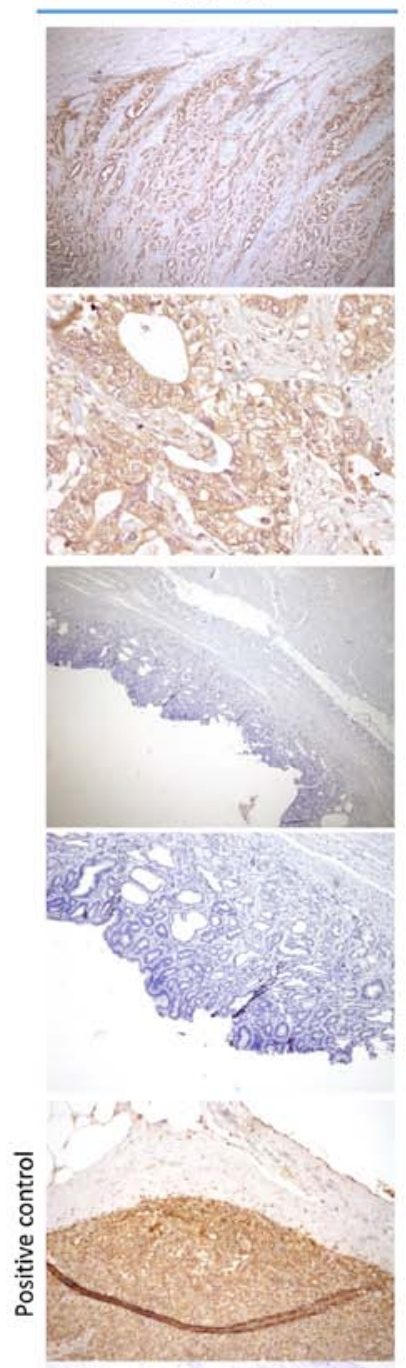

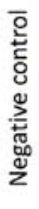

Figure 2. Immunohistochemical and immunofluorescence analysis of colonystimulating-factor-1 (CSF-1) and CSF receptor (CSF-1R) expression in gastric cancer (GC) tissues. (A) CSF-1 and CSF-1R expression in cancer tissues (left upper panel, CSF-1: magnification, x100; left lower panel, CSF-1: magnification, $\mathrm{x} 400$; right upper panel, CSF-1R: magnification, $\mathrm{x} 100$; right lower panel, CSF-1R: magnification, x400). (B) CSF-1 and CSF-1R expression in adjacent normal mucosa (left upper panel, CSF-1: magnification, x100; left lower panel, CSF-1: magnification, $\mathrm{x} 200$; right upper panel, CSF-1R: magnification, $\mathrm{x} 100$ right lower panel, CSF-1R: magnification, $\mathrm{x} 200$ ). (C) Positive and negative control of CSF-1 and CSF-1R staining in spleen (left upper panel, CSF-1 positive control: magnification, x200; left lower panel, CSF-1 negative control magnification, x200; right upper panel, CSF-1R positive control: magnification, x200; right lower panel, CSF-1R negative control: magnification, x200).

and VEGFA: $\mathrm{P}<0.0001, \mathrm{r}=0.99$; CSF-1 and FLT1: $\mathrm{P}<0.0001$, $\mathrm{r}=0.99$; CSF-1R and VEGFA: $\mathrm{P}<0.0001, \mathrm{r}=0.98$; $\mathrm{CSF}-1 \mathrm{R}$ and FLT1: $\mathrm{P}<0.0001, \mathrm{r}=0.99$, respectively) (Fig. 4B).

Collectively, these data, including the clinical significance of CSF-1/CSF-1R expression, multiple in vitro functional assays, and the positive correlation with angiogenetic factors, highlight the possibility that the CSF-1/CSF-1R axis may be

an attractive target for the development of novel treatment strategies for patients with GC.

\section{Discussion}

Accumulating evidence suggests the importance of the CSF-1/CSF-1R axis in various human cancers; however, the association between the expression of these proteins and their mechanistic role in driving GC has been unclear. In this study, to the best of our knowledge, we provide the first evidence supporting the clinical significance and functional importance of the CSF-1/CSF-1R axis in GC. First, the elevated expression of CSF-1 and CSF-1R in primary GC tissue was found to be significantly associated with the presence of lymph node and peritoneal metastasis, and an advanced TNM stage classification in patients with GC. Second, not only was a high co-expression of CSF-1/CSF-1R significantly associated with a poor survival, multivariate Cox regression analysis revealed that it was also an independent prognostic factor for OS and DFS in patients with GC. Third, a high CSF-1/CSF-1R co-expression was an independent risk factor for lymph node and peritoneal metastasis in patients with GC, suggesting that the CSF-1/CSF-1R axis may be involved in the progression of lymph node and peritoneal metastasis. Finally, a series of in vitro experiments demonstrated that the CSF-1/CSF-1R axis enhanced, not only the proliferation of GC cells, but also their migratory capacity and ability to resist anoikis.

Several studies have demonstrated associations between the overexpression of CSF-1 or CSF-1R and a poor oncological outcome. Richardsen et al performed tissue IHC analysis and found that the expression of CSF-1 and CSF-1R was higher in the prostate tumor cells and tumor stromal areas in patients with metastatic prostate cancer compared with patients with non-metastatic prostate cancer (28). Of note, another study analyzed the expression of CSF-1 and CSF-1R in tumors from 149 patients with non-gynecological leiomyosarcoma and found that the co-expression of CSF-1/CSF-1R in the primary tissues was a feasible prognostic biomarker for patients with this tumor (29). One of the major findings of this study was that the high expression of CSF-1 and CSF-1R in primary tissues was significantly associated with disease progression, recurrence, and a poor survival outcome in patients with GC. Furthermore, a high CSF-1/CSF-1R expression was an independent prognostic factor for OS and DFS in patients with GC. Our results are highly consistent with previous observations in various other types of cancer $(5,6)$. Collectively, these data suggest that the CSF-1/CSF-1R axis is intimately involved in $\mathrm{GC}$ disease progression and may be a surrogate parameter in predicting the prognosis of patients with GC.

Another key finding of this study was the intimate connection between the CSF-1/CSF-1R expression status and lymph node and/or peritoneal metastasis in patients with GC. Our results clearly demonstrate that the co-expression of CSF-1/CSF-1R is a potential predictor of recurrence and poor prognosis, and is an independent risk factor for lymph node and peritoneal metastasis in patients with GC. In current practice, there is a great need to discover feasible biomarkers that can identify patients with GC with lymph node or peritoneal metastasis. Metastasis to these areas is generally recognized to be one of the most important risk factors for 
A

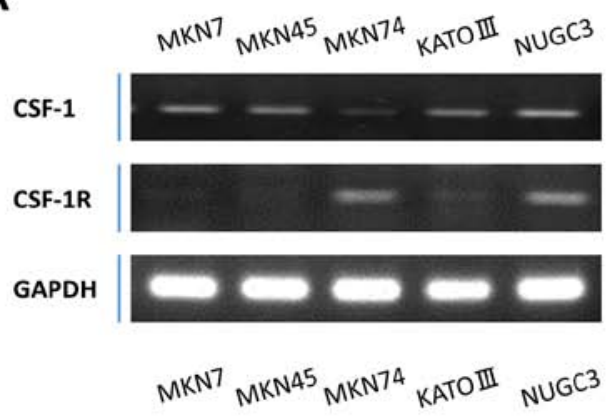

B

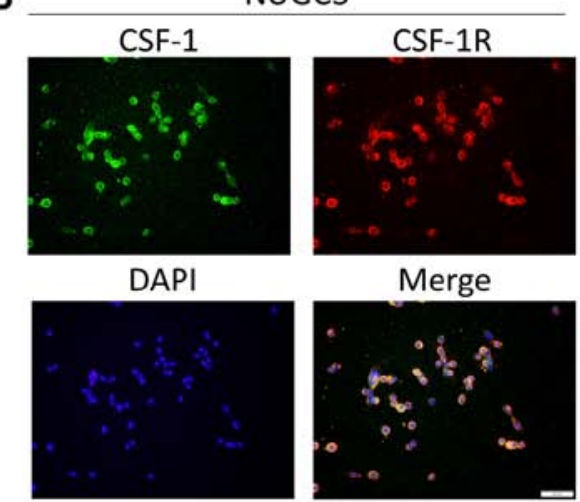

C

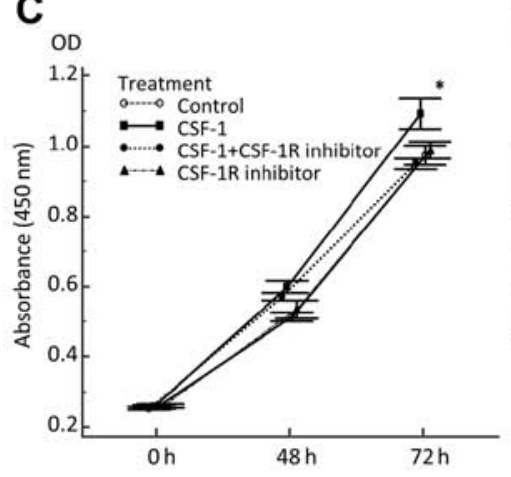

D

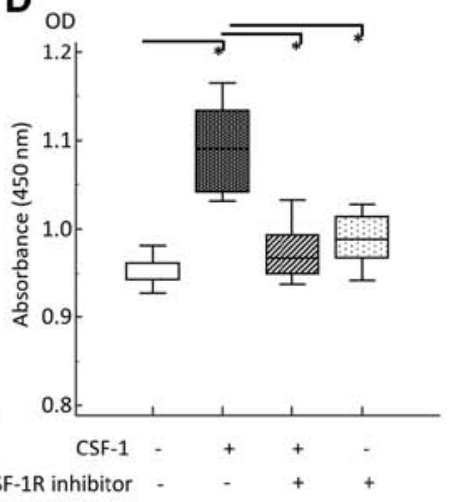

$\mathbf{E}$ ор

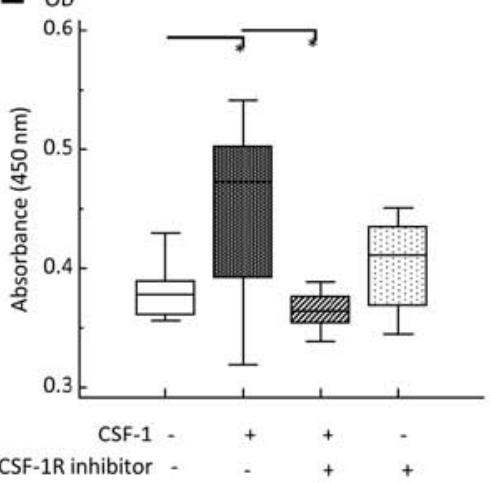

$\mathbf{F}$
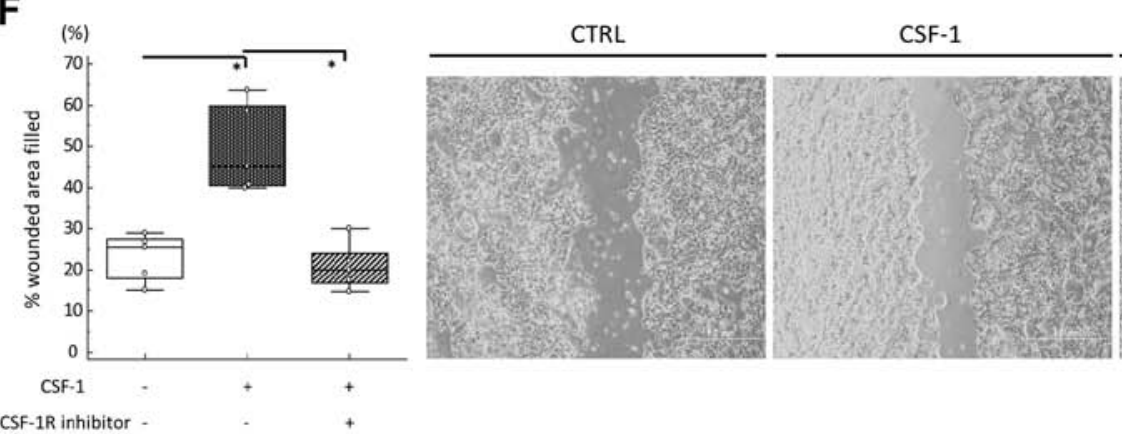
CSF-1+CSF-1R antibody

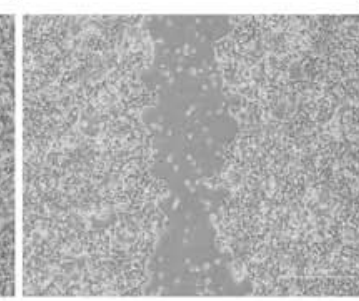

CSF-1R inhibitor

Figure 3. In vitro analyses of gastric cancer (GC) cell lines treated with recombinant human colony-stimulating-factor-1 (rhCSF-1) and a CSF receptor (CSF-1R) inhibitor. (A) A semi-quantitative RT-qPCR analysis of CSF-1 and CSF-1R transcripts in GC cell lines. (B) Immunofluorescent staining of NUGC3 cells (right upper panel, CSF-1: magnification, x200; left upper panel, CSF-1R: magnification, x200; right lower panel, DAPI: magnification, x200; left lower panel, Merge: magnification, x200). (C) Proliferation of MKN74 cells after 48 and $72 \mathrm{~h}$ of incubation. Cells were incubated with CSF-1 (100 ng/ml), CSF-1R inhibitor $(5 \mu \mathrm{M})$, or incubated with CSF-1R inhibitor $(5 \mu \mathrm{M})$ prior to the addition of CSF-1 (100 ng/ml). (D) Effect of CSF-1 and/or CSF-1R inhibitor on MKN74 cell proliferation at $72 \mathrm{~h}$, as assessed by MTT assay. (E) Anoikis assay of MKN74 cells following treatment with CSF-1 (100 ng/ml), CSF-1R inhibitor $(5 \mu \mathrm{M})$, or following incubation with CSF-1R inhibitor $(5 \mu \mathrm{M})$ prior to the addition of CSF-1 (100 ng/ml). After $18 \mathrm{~h}$, the assay, the number of viable cancer cells floating in low-attachment plates was measured by MTT assay. (F) Migration scratch assay of MKN74 cells following treatment with medium (negative control), CSF-1 (100 ng/ml), or following incubation with CSF-1R $(5 \mu \mathrm{M})$ prior to the addition of CSF-1 (100 ng/ml).

disease recurrence and a poor prognosis of patients with GC. The accurate detection of lymph node metastasis can assist in the selection of minimally invasive treatments, such as endoscopic resection or laparoscopic-assisted gastrectomy, for patients with early-stage GC. Furthermore, the precise prediction of peritoneal metastasis may aid the oncologist with decision-making regarding chemotherapeutic regimens and peri-operative intraperitoneal chemotherapy for patients with GC. Therefore, the identification of patients with GC with lymph node or peritoneal metastasis using molecular biomarkers, such as CSF-1/CSF-1R may assist the oncologist or surgeon in the decision-making process as to the proper treatment course to improve the prognosis of patients with GC.

This study uncovered a novel functional role for the CSF-1/CSF-1R axis in GC development. CSF-1 is a cytokine secreted by various cell types, and it regulates the survival, proliferation and differentiation of monocytes, osteoclasts and macrophages $(4,30,31)$. CSF-1 exerts its biological effects by binding to CSF-1R, which is a $165-\mathrm{kDa}$ glycoprotein encoded by the $\mathrm{c}-\mathrm{fms}$ proto-oncogene (32). The CSF-1/CSF-1R axis has been shown to play a pivotal role in macrophage and osteoclast function in patients with inflammatory disease (31), and CSF-1 
A

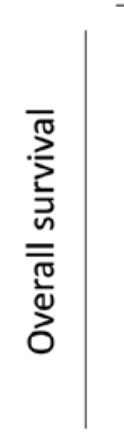

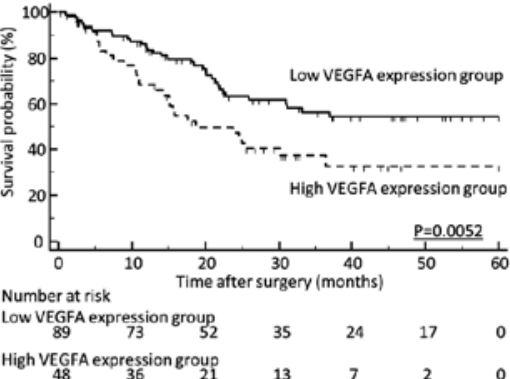

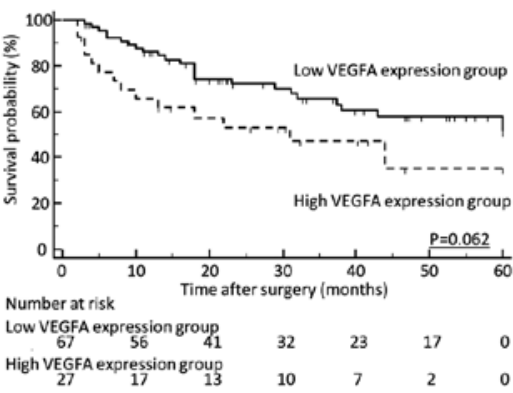

B
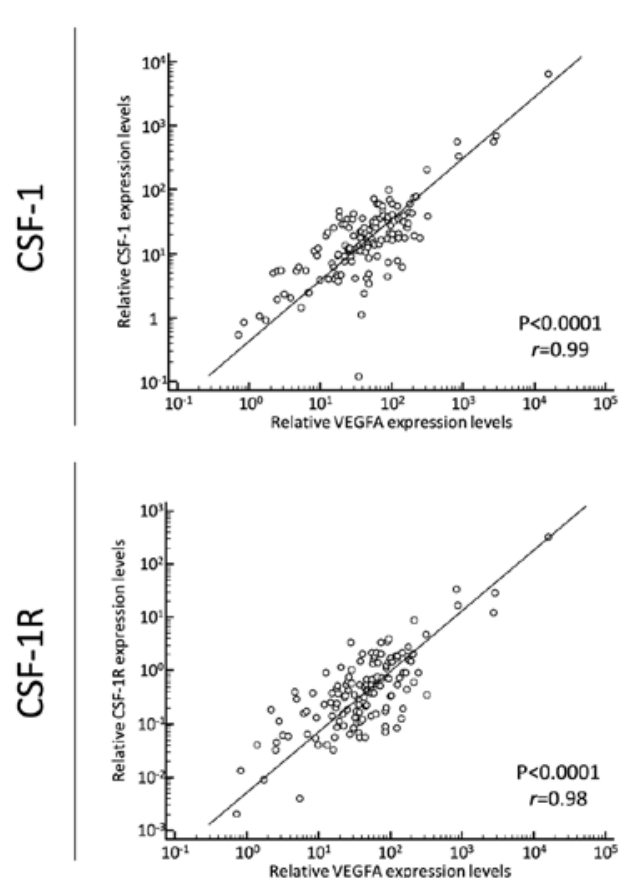

\section{FLT1}
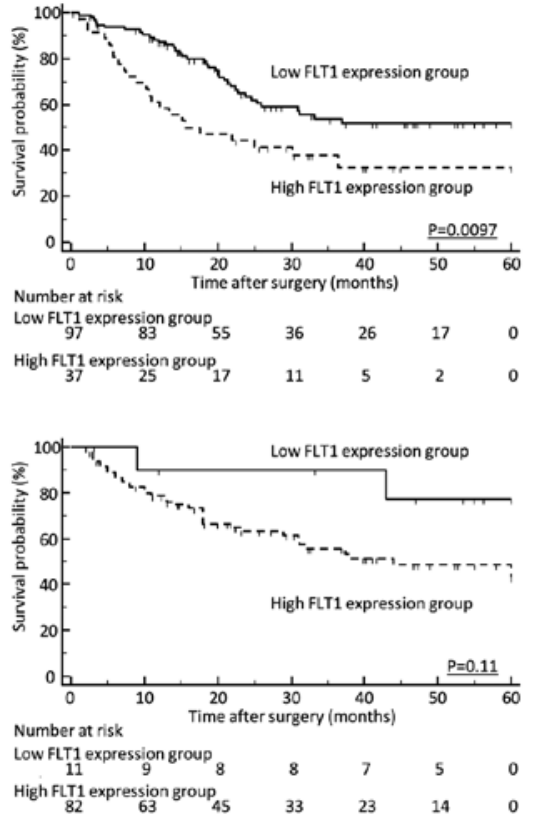

FLT1
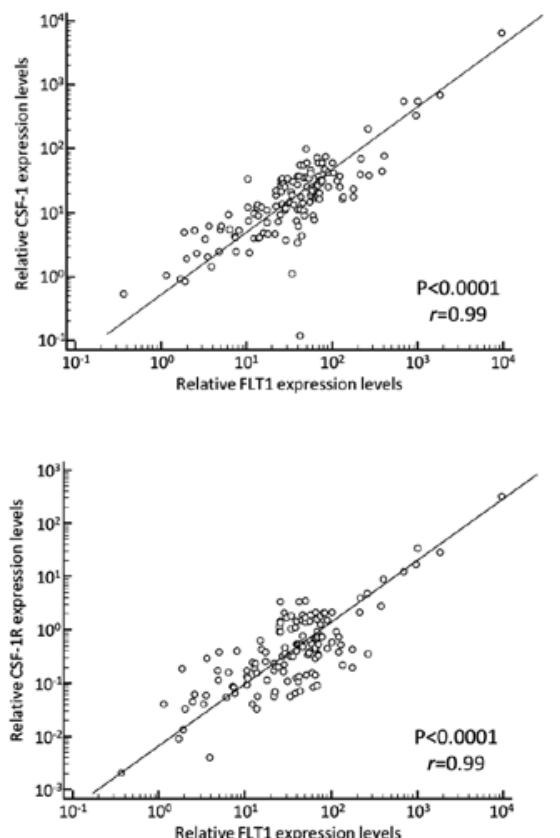

Figure 4. (A) (Upper panels) A high expression of vascular endothelial growth factor A (VEGFA) and Fms related tyrosine kinase 1 (FLT1) was significantly associated with a poor prognosis, compared with the low expression groups, for overall survival (OS; (VEGFA, P=0.0052; FLT1, P=0.0097; log-rank test). (Lower panels) A high expression of VEGFA and FLT1 also tended to be associated with a poor prognosis, compared with the low expression groups, for disease-free survival (DFS; VEGFA, P=0.062; FLT1, P=0.111; log-rank test). It should be noted here that for disease-free survival, patients with non-curative intent (stage IV) were not included; thus, the patient numbers differ from those for OS. In addition, several samples were not sufficient for amplification and were thus excluded. (B) Colony-stimulating-factor-1 (CSF-1) or CSF receptor (CSF-1R) expression levels positively correlated with VEGFA or FLT1 expression levels in gastric cancer tissues (CSF-1 and VEGFA: $\mathrm{P}<0.0001, \mathrm{r}=0.99$; CSF-1 and FLT1: $\mathrm{P}<0.0001, \mathrm{r}=0.99$; CSF-1R and VEGFA: $\mathrm{P}<0.0001, \mathrm{r}=0.98$; CSF-1R and FLT1: $\mathrm{P}<0.0001, \mathrm{r}=0.99$, respectively).

and CSF-1R expressed in tumor-associated macrophages enhances tumor progression and metastasis in various types of cancer (33-35). These findings suggest that the CSF-1/CSF-1R axis functions as a paracrine loop regulating cancer cells and blood-derived macrophages in the cancer microenvironment.
However, emerging evidence also supports an autocrine-loop function for the CSF-1/CSF-1R axis in cancer cells. For example, CSF-1/CSF-1R signaling activates signal transducer and activator of transcription-3 (Stat3), which promotes cell survival and proliferation in renal cell carcinoma (11). The 
same observation has been reported in other types of cancer, such as breast, lung and ovarian cancer $(7,12-14)$. The IHC analysis in our study revealed that CSF-1 and CSF-1R are mainly expressed in cancer cells, not in the cancer stroma, in GC tissues. Based on the combination of previous findings and our data, we hypothesized that the CSF-1/CSF-1R axis may be involved in GC development, and we investigated this in vitro using human GC cells treated with rhCSF-1 and a CSF-1R inhibitor. Consistent with previous data (7,11-14), we found that rhCSF-1 treatment enhanced the cell proliferative and migratory ability and CSF-1R inhibitor treatment suppressed these effects of rhCSF-1 in cultured GC cells. We demonstrated that the CSF-1/CSF-1R axis mediates a distinct oncogenic function, namely, anoikis resistance, in the GC cell line. Metastasis formation is currently recognized to consist of multiple steps $(36,37)$, and anoikis resistance plays a pivotal role in cancer cell survival during dissemination and metastasis (27). Of note, our study successfully demonstrated that the CSF-1 or CSF-1R expression levels positively correlated with the VEGFA or FLT1 expression levels in GC tissues. Although it remains unclear as to the direct evidence of CSF-1 upregulation via VEGF stimulation, several lines of evidence indicate that the CSF-1/CSF-1R axis can induce the production of VEGFA in various type of cells (38-41). Eubank et al demonstrated that recombinant human M-CSF induces freshly isolated normal human monocytes to produce and release the growth factor, VEGF, in a dose-dependent manner, and suggested an important role for M-CSF and monocytes in VEGF production and angiogenesis (39). Okazaki et al demonstrated that M-CSF stimulation increased VEGF protein vis Akt phosphorylation in culture medium of skeletal muscle cell, which was significantly inhibited by the addition of CSF-1R-neutralizing antibody (40). Furthermore, another research group demonstrated that CSF-1 induced VEGF-A overexpression in tumor-infiltrative macrophages and promoted tumor development via angiogenesis in colon cancer (41). These previous data combined with our novel findings suggested that the CSF1/CSF1R axis may promote metastatic spread via anoikis resistant with tumor angiogenesis, and highlighted the possibility that therapies targeting the CSF-1/CSF-1R axis may prove to be attractive for the development of novel treatment strategies for patients with GC.

Recently, Aharinejad et al assessed circulating CSF-1 concentration in pre-operative serum specimens from 1,260 patients with early-stage breast cancer (572 pts) and benign breast lesion (688 pts) and demonstrated that the serum CSF-1 concentration level was significantly increased in patients with early-stage breast cancer compared to those with benign breast lesion (42). A high serum CSF-1 concentration was significantly associated with nodal involvement and a poor survival in the patients with breast cancer (41). Although we could not evaluate the clinical impact of circulating CSF-1 concentration in GC due to the lack of matched specimens in the current study cohort, the above-mentioned evidence, together with our findings using tissue specimens, suggests the potential use of serum CSF-1 as a non-invasive prognostic biomarker in patients with GC.

In conclusion, this study provides novel evidence supporting the clinical significance and functional importance of the CSF-1/CSF-1R axis in GC. Our results demonstrate the clinical feasibility of CSF-1 and CSF-1R as prognostic and predictive biomarkers for lymph node and peritoneal metastasis in patients with GC. Our in vitro analysis also revealed a functional role for the CSF-1/CSF-1R axis in GC development. It can thus be concluded that the CSF-1/CSF-1R axis may have clinical utility as a prognostic and predictive biomarker and, potentially, as a therapeutic target in GC.

\section{Acknowledgements}

The authors would like to thank Mrs. Yuki Orito, Mrs. Amphone Okada and Ms. Aya Narumi (Department of Gastrointestinal and Pediatric Surgery, Mie University, Tsu, Japan) for providing excellent technical assistance.

\section{Funding}

YO was supported in part by a Grant-in-Aid for Scientific Research from the Takeda Science Foundation, Japan. This study was also supported in part by a Grant-in-Aid for Scientific Research (no. 25462018) from the Ministry of Education, Culture, Sports, Science and Technology, Japan to MO.

\section{Availability of data and materials}

All data generated or analyzed during this study are included in this published article.

\section{Authors' contributions}

Study concept and design (YO, YT, CM and MKu); provision of samples (TI, MKa, HY, HF, SS, MO, KT, YI, MT and TA); acquisition of data (YO, YT, TI, MKa, HY, HF, SS, MO, KT, YI and $\mathrm{CM}$ ); analysis and interpretation of data (YO, YT, MKa, HY, HF, SS, MO, KT, YI, MT and TA); statistical analysis (YO and YT); drafting of the manuscript (YO, YT, CM and MKu). All authors have read and approved the final manuscript.

\section{Ethics approval and consent to participate}

For the use of patient samples, written informed consent was obtained from each patient, and the study was approved by the Institutional Review Boards of Mie University (no. 2215).

\section{Consent for publication}

Not applicable.

\section{Competing interests}

The authors declare that they have no competing interests.

\section{References}

1. Torre LA, Bray F, Siegel RL, Ferlay J,Lortet-Tieulent J and Jemal A: Global cancer statistics, 2012. CA Cancer J Clin 65: 87-108, 2015.

2. Jemal A, Siegel R, Ward E, Hao Y, Xu J and Thun MJ: Cancer statistics, 2009. CA Cancer J Clin 59: 225-249, 2009.

3. Gill K, Kirma N, Gunna VS, Santanam N, Parthasarathy S and Tekmal RR: Regulation of colony stimulating factor-1 (CSF-1) in endometrial cells: Glucocorticoids and oxidative stress regulate the expression of CSF-1 and its receptor $\mathrm{c}-\mathrm{fms}$ in endometrial cells. Fertil Steril 76: 1005-1011, 2001. 
4. Pixley FJ and Stanley ER: CSF-1 regulation of the wandering macrophage: Complexity in action. Trends Cell Biol 14: 628-638, 2004

5. Yang L, Wu Q, Xu L, Zhang W, Zhu Y, Liu H, Xu J and Gu J: Increased expression of colony stimulating factor-1 is a predictor of poor prognosis in patients with clear-cell renal cell carcinoma. BMC Cancer 15: 67, 2015.

6. Komohara Y, Ohnishi K, Kuratsu J and Takeya M: Possible involvement of the M2 anti-inflammatory macrophage phenotype in growth of human gliomas. J Pathol 216: 15-24, 2008.

7. Patsialou A, Wyckoff J, Wang Y, Goswami S, Stanley ER and Condeelis JS: Invasion of human breast cancer cells in vivo requires both paracrine and autocrine loops involving the colonystimulating factor-1 receptor. Cancer Res 69: 9498-9506, 2009.

8. Soares MJ, Pinto M, Henrique R, Vieira J, Cerveira N, Peixoto A, Martins AT, Oliveira J, Jerónimo C and Teixeira MR: CSF1R copy number changes, point mutations, and RNA and protein overexpression in renal cell carcinomas. Mod Pathol 22: 744-752, 2009.

9. Ide H, Seligson DB, Memarzadeh S, Xin L, Horvath S, Dubey P Flick MB, Kacinski BM, Palotie A and Witte ON: Expression of colony-stimulating factor 1 receptor during prostate development and prostate cancer progression. Proc Natl Acad Sci USA 99: 14404-14409, 2002.

10. Chambers SK, Kacinski BM, Ivins CM and Carcangiu ML: Overexpression of epithelial macrophage colony-stimulating factor (CSF-1) and CSF-1 receptor: A poor prognostic factor in epithelial ovarian cancer, contrasted with a protective effect of stromal CSF-1. Clin Cancer Res 3: 999-1007, 1997.

11. Komohara Y, Hasita H, Ohnishi K, Fujiwara Y, Suzu S, Eto M and Takeya M: Macrophage infiltration and its prognostic relevance in clear cell renal cell carcinoma. Cancer Sci 102: 1424-1431, 2011.

12. Hung JY, Horn D, Woodruff K, Prihoda T, LeSaux C, Peters J, Tio F and Abboud-Werner SL: Colony-stimulating factor 1 potentiates lung cancer bone metastasis. Lab Invest 94: 371-381, 2014.

13. Goswami S, Sahai E, Wyckoff JB, Cammer M, Cox D, Pixley FJ, Stanley ER, Segall JE and Condeelis JS: Macrophages promote the invasion of breast carcinoma cells via a colony-stimulating factor-1/epidermal growth factor paracrine loop. Cancer Res 65 : 5278-5283, 2005.

14. Menke J, Kriegsmann J, Schimanski CC, Schwartz MM, Schwarting A and Kelley VR: Autocrine CSF-1 and CSF-1 receptor coexpression promotes renal cell carcinoma growth. Cancer Res 72 187-200, 2012

15. Okugawa Y, Toiyama Y, Hur K, Toden S, Saigusa S, Tanaka K, Inoue Y, Mohri Y, Kusunoki M, Boland CR, et al: Metastasisassociated long non-coding RNA drives gastric cancer development and promotes peritoneal metastasis. Carcinogenesis 35: 2731-2739, 2014.

16. Okugawa Y, Tanaka K, Inoue Y, Kawamura M, Kawamoto A, Hiro J, Saigusa S, Toiyama Y, Ohi M, Uchida K, et al: Brain-derived neurotrophic factor/tropomyosin-related kinase $\mathrm{B}$ pathway in gastric cancer. Br J Cancer 108: 121-130, 2013.

17. Okugawa Y, Inoue Y, Tanaka K, Kawamura M, Saigusa S, Toiyama Y, Ohi M, Uchida K, Mohri Y and Kusunoki M: Smad interacting protein 1 (SIP1) is associated with peritoneal carcinomatosis in intestinal type gastric cancer. Clin Exp Metastasis 30: 417-429, 2013

18. Okugawa Y, Toiyama Y, Tanaka K, Matsusita K, Fujikawa $\mathrm{H}$ Saigusa S, Ohi M, Inoue Y, Mohri Y, Uchida K, et al: Clinical significance of Zinc finger E-box Binding homeobox 1 (ZEB1) in human gastric cancer. J Surg Oncol 106: 280-285, 2012

19. Toiyama Y, Tanaka K, Kitajima T, Shimura T, Imaoka H, Mori K, Okigami M, Yasuda H, Okugawa Y, Saigusa S, et al: Serum angiopoietin-like protein 2 as a potential biomarker for diagnosis, early recurrence and prognosis in gastric cancer patients. Carcinogenesis 36: 1474-1483, 2015

20. Toiyama Y, Yasuda H, Saigusa S, Matushita K, Fujikawa H, Tanaka K, Mohri Y, Inoue Y, Goel A and Kusunoki M: Co-expression of hepatocyte growth factor and c-Met predicts peritoneal dissemination established by autocrine hepatocyte growth factor/c-Met signaling in gastric cancer. Int J Cancer 130 : 2912-2921, 2012

21. Japanese-Gastric-Cancer-Association. Jpn Classificacion Gastric Carcinoma 14: 10-25, 2010

22. Tanaka K, Mohri Y, Nishioka J, Kobayashi M, Ohi M, Miki C, Tonouchi H, Nobori T and Kusunoki M: Neurotrophic receptor, tropomyosin-related kinase B as an independent prognostic marker in gastric cancer patients. J Surg Oncol 99: 307-310, 2009.
23. Conway JG, McDonald B, Parham J, Keith B, Rusnak DW, Shaw E, Jansen M, Lin P, Payne A, Crosby RM, et al: Inhibition of colony-stimulating-factor-1 signaling in vivo with the orally bioavailable cFMS kinase inhibitor GW2580. Proc Natl Acad Sci USA 102: 16078-16083, 2005.

24. Conway JG, Pink H, Bergquist ML, Han B, Depee S, Tadepalli S, Lin P, Crumrine RC, Binz J, Clark RL, et al: Effects of the cFMS kinase inhibitor 5-(3-methoxy-4-((4-methoxybenzyl)oxy)benzyl) pyrimidine-2,4-diamine (GW2580) in normal and arthritic rats. J Pharmacol Exp Ther 326: 41-50, 2008.

25. Okugawa Y, Toiyama Y, Toden S, Mitoma H, Nagasaka T, Tanaka K, Inoue Y, Kusunoki M, Boland CR and Goel A: Clinical significance of SNORA42 as an oncogene and a prognostic biomarker in colorectal cancer. Gut 66: 107-117, 2017.

26. Frisch SM and Francis H: Disruption of epithelial cell-matrix interactions induces apoptosis. J Cell Biol 124: 619-626, 1994.

27. Eccles SA and Welch DR: Metastasis: Recent discoveries and novel treatment strategies. Lancet 369: 1742-1757, 2007.

28. Richardsen E, Uglehus RD, Due J, Busch C and Busund LT: The prognostic impact of M-CSF, CSF-1 receptor, CD68 and CD3 in prostatic carcinoma. Histopathology 53: 30-38, 2008.

29. Espinosa I, Beck AH, Lee $\mathrm{CH}$, Zhu S, Montgomery KD, Marinelli RJ, Ganjoo KN, Nielsen TO, Gilks CB, West RB, et al: Coordinate expression of colony-stimulating factor- 1 and colony-stimulating factor-1-related proteins is associated with poor prognosis in gynecological and nongynecological leiomyosarcoma. Am J Pathol 174: 2347-2356, 2009.

30. Yu W, Chen J, Xiong Y, Pixley FJ, Yeung YG and Stanley ER: Macrophage proliferation is regulated through CSF-1 receptor tyrosines 544, 559, and 807. J Biol Chem 287: 13694-13704, 2012

31. Chitu V and Stanley ER: Colony-stimulating factor-1 in immunity and inflammation. Curr Opin Immunol 18: 39-48, 2006.

32. Sherr CJ, Rettenmier CW, Sacca R, Roussel MF, Look AT and Stanley ER: The c-fms proto-oncogene product is related to the receptor for the mononuclear phagocyte growth factor, CSF-1. Cell 41: 665-676, 1985.

33. Lin EY, Nguyen AV, Russell RG and Pollard JW: Colonystimulating factor 1 promotes progression of mammary tumors to malignancy. J Exp Med 193: 727-740, 2001.

34. Aharinejad S, Abraham D, Paulus P, Abri H, Hofmann M, Grossschmidt K, Schäfer R, Stanley ER and Hofbauer R: Colonystimulating factor-1 antisense treatment suppresses growth of human tumor xenografts in mice. Cancer Res 62: 5317-5324, 2002.

35. Wyckoff J, Wang W, Lin EY, Wang Y, Pixley F, Stanley ER, Graf T, Pollard JW, Segall J and Condeelis J: A paracrine loop between tumor cells and macrophages is required for tumor cell migration in mammary tumors. Cancer Res 64: 7022-7029, 2004.

36. Fidler IJ: Critical determinants of metastasis. Semin Cancer Biol 12: 89-96, 2002.

37. Chan DA and Giaccia AJ: Hypoxia, gene expression, and metastasis. Cancer Metastasis Rev 26: 333-339, 2007.

38. Curry JM, Eubank TD, Roberts RD, Wang Y, Pore N, Maity A and Marsh CB: M-CSF signals through the MAPK/ERK pathway via $\mathrm{Sp} 1$ to induce VEGF production and induces angiogenesis in vivo. PLoS One 3: e3405, 2008.

39. Eubank TD, Galloway M, Montague CM, Waldman WJ and Marsh CB: M-CSF induces vascular endothelial growth factor production and angiogenic activity from human monocytes. J Immunol 171: 2637-2643, 2003.

40. Okazaki T, Ebihara S, Takahashi H, Asada M, Kanda A and Sasaki H: Macrophage colony-stimulating factor induces vascular endothelial growth factor production in skeletal muscle and promotes tumor angiogenesis. J Immunol 174: 7531-7538, 2005.

41. Zins K, Abraham D, Sioud M and Aharinejad S: Colon cancer cell-derived tumor necrosis factor-alpha mediates the tumor growth-promoting response in macrophages by up-regulating the colony-stimulating factor-1 pathway. Cancer Res 67: 1038-1045, 2007.

42. Aharinejad S, Salama M, Paulus P, Zins K, Berger A and Singer CF: Elevated CSF1 serum concentration predicts poor overall survival in women with early breast cancer. Endocr Relat Cancer 20: 777-783, 2013. 